\title{
A point of view
}

\section{What has technology done to gastroenterology?}

Technology is as old as man. As Benjamin Franklin aptly said, man has always been a tool making animal, and his capacity to make tools has been applied to medicine since ancient times. Medicine is essentially a craft and technology, as much as science, has therefore been an essential part of its practice. Perhaps one of the earliest technologies was the application of splints to broken limbs. The splints found on the legs of Egyptian mummies from the Old Kingdom are examples of prehistoric medical technology that serve to emphasise that medical technology has always been with us, and that technology is older than science.

Technology, even more than science, has been responsible for major developments in the practice of gastroenterology. There are of course many areas of gastroenterology which owe everything to the application of scientific knowledge. The dramatic reduction in the world mortality from cholera, for example, was achieved as a result of the application of scientific knowledge and what we know of the effect of gluten in causing coeliac disease was the result of careful scientific observation. Equally, in hepatology, scientific knowledge has greatly increased our understanding of the different types of hepatitis and promises now, through the development of vaccines, to do something effective for a common disease of the liver for the first time.

The story of modern antibiotics is perhaps the most striking example of the success of science in alleviating the sufferings of mankind, but in the development of gastroenterology technology has at the same time been of vital importance.

Diagnostic technology in medicine began with Laennec's invention of the stethoscope in the early 19th century and since then there has been a dramatic increase in the availability of techniques for diagnosis and treatment. In gastroenterology, the earliest techniques were surgical, the development of anaesthetics and antiseptic techniques during the second half of the 19th century allowing surgeons to operate within the abdomen for the first time. Intubation techniques were pioneered by the laryngologists who introduced the method of examining the larynx directly, a technique that so sadly misled the British physician, Sir Morrell McKenzie, when he treated the dying Kaiser Frederick during his short reign in 1888 . Endoscopy of the stomach and colon followed soon after and were the first techniques to establish the gastroenterologist as a specialist, even though it was not until Schindler's pioneering work that effective gastroscopy was developed. The discovery of $x$-rays and the use of barium techniques for examination of the entire gastrointestinal tract opened up a whole new world for the gastroenterologist. He could now diagnose dyspepsia as due to peptic ulceration, discover unsuspected tumours in the colon far beyond 
the reach of his sigmoidoscope and investigate the small intestine for the first time.

In recent decades the pace of technological advance has increased. For the hepatologist, the introduction of liver biopsy dramatically increased diagnostic certainty, even if it did not at first improve the prognosis of patients with liver disease. It was also a technique associated with a distinct morbidity and mortality, so that it became important to balance the benefit that the new technique could bring against the possible damage that could be caused. Many physicians in Britain, whose doctrine of primum non nocere was the cornerstone of their medical philosophy, at first opposed the introduction of liver biopsy, particularly when used for purposes of scientific investigation. Colonic biopsy has been practiced since the introduction of sigmoidoscopic techniques but it was the development of gastric biopsy in 1948 by Wood in Australia that led to the first successful biopsies of the duodenum and the small intestine. Wood's tube for gastric biopsy was advanced by Royer ${ }^{2}$ and by Shiner ${ }^{3}$ through the pylorus into the duodenum and small intestine, the tube was made longer and a new era in the investigation of small intestinal disease had begun. Perhaps the best example of medical ingenuity in this era was Crosby's invention of his remarkable jejunal biopsy capsule, which enabled investigators of the American Army in Puerto Rico to define the pathological lesion of the small intestine in tropical sprue. The recognition of the characteristic pathology of coeliac disease, and many other conditions, was made possible by the introduction of this simple, low cost technology. At the same time studies of absorption using biochemical and radioisotopic techniques revolutionised our understanding of small intestinal disorders.

As everyone recognises, the technology which has now become so important for the successful practice of modern gastroenterology was the development of fibre optic instruments for endoscopic examination. It was at this time that gastroenterological techniques began to be expensive. In view of the importance of these developments, the story of fibre optic endoscopy is perhaps worth recounting in some detail.

In 1952, a British gastroenterologist, Dr Hugh Gainsborough of St George's Hospital in London, met Harold Hopkins, then working at the Imperial College of Science and Technology. Hopkins had already made his name as the inventor of the zoom lens. Gainsborough, to use Hopkins' own words, was 'pretty well appalled by the use of the old rigid gastroscope'. (Personal communication). He asked Hopkins whether it would not be possible to have something flexible like a Ryle's tube which could be passed much more easily. It was this suggestion that encouraged Hopkins to think about the matter. A few months later he formed the idea of a coherent glass fibre bundle for carrying an optical image along a flexible path. In July 1952, having satisfied himself that a single thin fibre could transmit light, he obtained a grant from the Royal Society, the amount being $£ 750$ for each of two years, and he put his graduate student, N S Kapany, on to the project. Using commercially available glass fibre, they were able to produce a successful image-transmitting bundle by late 1953 and the work was published in Nature in early January, $1954 .{ }^{4}$ There were, writes Hopkins, many enquiries after the publication of this article but sadly none from industry. One of those enquiries was of particular note to gastroenterologists for it was from Sir Francis Avery Jones, doyen of 
British gastroenterological clinicians, who at once understood the major importance of Hopkins and Kapany's discovery. Avery Jones had trained a young South African doctor, Dr Basil Hirschowitz, in the traditional techniques of rigid endoscopy at his clinic in the Central Middlesex Hospital in London. Hirschowitz was now working in Ann Arbor. Michigan, with Dr Marvin Pollard. He, like Avery Jones, had the vision to see the potential of Hopkins' work for the future of gastroenterology and he made haste to visit London in early 1954 . He recorded later that he found Hopkins to be 'warm and friendly' and one of the 'most modest and generous of men'. ${ }^{5}$ Hirschowitz interested Dr Pollard in the idea of developing a fibre optic instrument for endoscopy and together they tried unsuccessfully to persuade Kapany to work with them. Kapany, however. declined their offer and by 1955 Hirschowitz was collaborating with Larry Curtis at Ann Arbor in the production of a fibrescope. They succeeded in doing this by early 1957 when Hirschowitz passed the 'rather thick forbidding rod' on himself, swallowing it as he later wrote, 'over the protest of his unanaesthetised pharynx' ${ }^{5}$ The first fibre optic examinaton of the stomach of a patient soon followed, the instrument being used to carry out an examination on the wife of a dental student in the University Hospital at Ann Arbor.

The next step was clearly the production of a commercially viable instrument by industry but this was to prove much more difficult than the early experimental work. At first no industrial firm in the United States or in Britain was willing to help develop the fibrescope. Finally, in the summer of 1957, American Cystoscope Makers Inc. (ACMI) agreed to make fibrescopes under licence. By now Hirschowitz was director of the Gastroenterology Unit in Birmingham, Alabama. The earliest commercial fibrescope was tested there in a patient in 1960 and the first results, using further modifications of the instrument, were reported in the Lancet in May $1961 .^{6}$

The remainder of the story belongs to Japan. In 1962, Professor Tadayoshi Takemoto, now Professor in Yamaguchi University School of Medicine, imported a commercially available Hirschowitz gastro-duodenal fibrescope from the USA. The moment was particularly propitious for Japan at that time provided a particularly fertile field for the development of fibre optic endoscopy. Japanese surgeons working in Tokyo, concerned at the high incidence of gastric cancer in their community, had already in the early 1950 s developed a gastrocamera in association with the Olympus Company for the purpose of early diagnosis, and by 1955 more than 1000 patients had been examined at Tokyo University using this technique (personal communication). There was therefore in Japan a community of physicians and surgeons, as well as a commercial organisation, highly sympathetic to the use of new techniques in the investigation of gastro-intestinal disease. Takemoto wrote later that when he took the USA made fibrescope in his hands for the first time, he at once predicted that the gastrocamera would be replaced (personal communication). It was in this environment that Takemoto, together with the Machida Company and with Olympus, rapidly developed the new generation of fibre optic instruments for endoscopy that have swept the world. The first Japanese endoscopes were on the market within a year of Takemoto's importation into Japan of the Hirschowitz instrument. Hopkins records that Olympus 
presented him with their first fibre optic bundle with the gracious comment that 'it ought to be in the hands of the father of the subject' (personal communication). Excellence of design, performance, and reliability have contributed to the continued success of the Japanese manufacturers. It was in Japan that the first colonoscopes were developed and again this was preceded by photographic instruments. In 1957, Professor Matsunaga of Hirosaki University designed a camera, similar to the gastrocamera, for use in the colon, in cooperation with the Olympus Company, and it was with Olympus that Matsunaga and his associates were able to develop the colono-fibrescope which came on to the market in 1969.

Other techniques of visualising internal organs have, of course, been practiced, particularly in western Europe, for many decades. The hepatologists have used peritoneoscopy and radiological techniques such as splenic venography have a long history. In recent years, however, there has been an increasing emphasis on non-invasive techniques of investigation and the development of ultrasound, CT scanning and nuclearmagnetic resonance have reflected this trend. These new techniques, however, are immensely more expensive than even the most sophisticated endoscopic clinic and the new era has therefore been dominated not only by increasing complexity of investigative techniques but also by increasing costs. Methods of diagnostic imaging, which now include gamma cameras for the localisation of radio labelled compounds, digital vascular imaging, ultrasound machines of increasing versatility and sophisticated immunological techniques for tumour localisation, threaten to consume a greater proportion of the budget of a general or university hospital than ever before. Whether any will be able to afford the cost of a laser machine, or whether it will even really be needed, remain unanswered questions. It can be confidently predicted that the rapid pace of technological advance will continue. The use of modern techniques of molecular and cell biology is already promising to have a profound effect on the control of gastrointestinal infections, viral, bacterial and parasitic, to say nothing of the techniques which have made possible the development of drugs such as the $\mathrm{H}_{2}$-receptor antagonists.

No one can deny that the development of technology as applied to gastroenterology has radically changed medical practice in recent decades. Yet certain questions have to be asked. Is too much endoscopy being carried out, the technique too often providing nothing more than occupational therapy or financial advantage to the gastroenterologist? Has the new technology been beneficial to the patients whom we treat? Is it too expensive? Is it safe? And has the gastroenterologist simply become a medical technician who carries out a series of complex but personally satisfying techniques? ${ }^{7}$

These questions must be answered, particularly in an era when the threat of nuclear war has encouraged the development of a stronger than ever antitechnology lobby. There is nothing new in the attack on new technology. When steam trains were first introduced, there were those who predicted that the human body would be unable to withstand a speed of more than 10 miles an hour. In the heyday of the Victorian era, when technological development was at its height, Emerson, the American poet, warned that 'things are in the saddle and ride mankind.' Henry Adams, an American visiting the Paris Exhibition in 1900, felt overwhelmed by what 
he saw as the excesses of technology. Disenchantment with technology was expressed in a particular dramatic and generalised way in the early 1930s by Aldous Huxley, in his extraordinary novel, Brave New World, whose predictions of the future of reproductive technology are uncanny. Disillusionment with technology was also portrayed in Charlie Chaplin : film Modern Times, where the depersonalising effect of a contemporary production line was brilliantly depicted. ${ }^{8}$

The current attack on modern medical technology by writers such as Illich and Kennedy is therefore not surprising, nor should it be wondered at. As in other areas of human activity, medical technology is attacked as being dehumanising, reducing the patient to a mere body in the midst of a mass of machinery. It is also seen to alter the whole image of the doctor whose older position as a beloved and caring physician is replaced in the eyes of the critics of modern medicine by that of a medical Dr Strangelove in love with techniques for their own sake. Of course, gastroenterologists do not share these views. They believe that modern technological developments in medicine - for example, the ability to replace damaged heart valves or coronary arteries, or to treat renal failure with dialysis or transplantation, are as great a reflection of the nobility of the human spirit as any of the works of the great scientists, painters, or writers of the past. Nor is there any reason why technology as applied to medicine should be more dehumanising than technology applied to travel by jet airplanes or communication by telephone using space satellites. It is essential in medicine, as in any other of man's activities, that technology used with intelligence and compassion be developed in the service of mankind. There is surely no field of human activity that has a greater claim on man's ingenuity.

No gastroenterologist would doubt that technological advances have benefited their patients. Quite apart from techniques of visualisation, to be able to diagnose coeliac disease accurately, to remove a gall stone from the biliary passages without recourse to surgery, and to diagnose and treat a hepatic disorder such as chronic hepatitis are all examples of the beneficial effects of new technology.

Yet is is generally true that in many areas of medicine new techniques have been introduced without sufficient assessment and there are questions to be answered in the introduction of new technology. These questions are particularly pressing at this time in view of the expense faced by health authorities and by patients themselves. First, does the technique do what is claimed for it? Is it efficacious in the individual patient? Is a diagnostic technique reliable, valid, sensitive, and specific? In the introduction of new treatments, have well designed randomised controlled trials been carried out? How much of the technology is required to provide a service? In particular, when a new technique is introduced is it just an 'add-on' service. satisfying the curiosity of the medical practitioner but doing little to increase his diagnostic or therapeutic accuracy? ${ }^{7}$

Sadly, in the past there has frequently been a failure of the medical profession to answer these questions and it is for this reason that modern medical administrators and health economists are themselves questioning whether the expensive things that are done are really necessary. In view of the escalating costs of health care world wide, they are right to do so. But has the medical profession any way of ensuring that it can answer these 
questions itself before lay analysts show our over enthusiasm in the use of technology? In many countries there are no safeguards against an excessive use of technology. In a health care system based on private practice and the private provision of insurance, as in the United States, many techniques have been introduced without analysis and the costs have simply been added to the cost paid by the individual patient. A powerful resistance to this system has, however, been introduced by the health care insurance companies and the government who are now insisting that investigative and other techniques carried out for a particular clinical problem are controlled by agreed guidelines. It is for this reason that the introduction of the concept of 'diagnosis related groups', a specific agreed series of diagnostic procedures for any given condition, is revolutionising not only the costs of medical practice in the United States but also the funding of University Medical Schools.

In a nationalised public health care system, as in Sweden or the United Kingdom, the situation has been different. In Britain, for example, the Department of Health gives an annual budget to each of the regional health authorities in England and Wales. These regional authorities then share their budget among the district health authorities who are responsible for providing health care to a given community. It is the regional health authority that controls capital costs for expensive technology. For this reason, the National Health Service has been increasingly insisting that all medical technologies be accurately assessed before districts and regions nationwide proceed with the provision of expensive equipment, which in the past has often been bought to maintain the prestige and status of an institution, rather than for specific purposes of health care. The introduction of CT scanning for neurological assessment in Britain was assessed in one unit before the Health Department agreed to the introduction of this expensive technology elsewhere, and the use of the whole body CT scanner was carefully investigated by Dr Louis Kreel at the Clinical Research Centre and Northwick Park Hospital before further scanners were authorised. Similarly, the Department of Health, together with the Medical Research Council, are currently undertaking a systematic analysis of the use of NMR for diagnostic imaging at Hammersmith Hospital and there will be only limited introduction of such expensive technology before this is completed.

It should at this stage be emphasised that any national expenditure on what is called high technology medicine is relatively small when compared with expenditure on technology associated with travel, communication and particularly defence. It must be stressed further that the overall costs for technology throughout any health care system are due predominantly to the multiplicity of small items required rather than to the expenditure on single expensive items of equipment. The provision on a wide scale of disposable items of equipment, ECG machines, prostheses for joint replacement, cardiac pacemakers, endoscopes, liver biopsy needles and a host of other techniques less glamorous than CT scanners or NMR are in toto much more costly than the techniques of so called high technology medicine. It is for this reason that assessment of technology must be much more widely applied than merely to apparently expensive techniques. Our present organisational structure does not allow for this nor has a medical profession that has consistently argued whether medicine is an art or a 
science paid enough attention to the importance of technology. A great deal of modern medicine depends more on technology than on science. Applied science and technology do not at present enjoy as much kudos in western society as science, and the Nobel prize won by Hounsfield for the development of CT scanning has been described by at least one American scientist as being awarded for 'mere technology'.

Finally, what has the new technology done to those who practice gastroenterology? There is a real danger that some gastroenterologists are allowing themselves to become technicians rather than professional colleagues to be consulted when their help is needed. If another doctor asks for a technique such as endoscopy or liver biopsy to be carried out and the gastroenterologist simply responds by carrying out the technique, he is behaving not as a consultant but as a technician. It is essential that gastroenterologists should avoid this danger. They should insist that they are consulted about the patient and his or her problem as a whole and it should then be for the gastroenterologist to decide what investigations are appropriate. This is the only way to ensure in the new era of technology that gastroenterology retains its position as the major speciality of internal medicine and surgery.

I am grateful to Sir Francis Avery Jones, Dr Basil Hirschowitz, Professor Harold Hopkins, FRS, Professor Tadayoshi Takemoto and Professor Yutaka Yoshida for their help in the preparation of this paper.

Clinical Research Centre

C C BOOTH

\section{Harrow, Middlesex}

Schlussvortrag given at the 39th Annual Meeting of the Deutsche Gesellschaft fur Verdauungs und Stoffwechsel Krankheiten, Berlin, 3-6 October. 1984.

\section{References}

1 Laennec RTH. De L'auscultation Mediate. Paris, Brosson JA, and Chaude JS, 1819.

2 Royer M, Croxatto O, Biempica L, Balcazar Morrison AJ. Biopsie duodenal por aspiracion control radio-scopico. Pren Med Argent 1955; 42: 2515-9.

3 Shiner M. Jejunal biopsy tube. Lancet 1956; 1: 85.

4 Hopkins HH, Kapany NS. A flexible fiberscope using static scanning. Nature (London) 1954; 173: 39-41.

5 Hirschowitz BI. A personal history of the fiberscope. Gastroenterology 1979; 76: 864-9.

6 Hirschowitz BI. Endoscopic examination of the stomach and duodenal cap with a fiberscope. Lancet 1961; 1: 1074-8.

7 Council for Science and Society. Expensive medical techniques. London: Calvert's Press, 1982.

8 Conceptions of technology. Encyclopedia Britannica 15th ed 1984; 18: 21-4. 